\title{
MOBILIDADE URBANA: UMA ANÁLISE DA ACESSIBILIDADE NO BAIRRO DE NOVA BETÂNIA EM MOSSORÓ-RN
}

\author{
C. LIBERALINO e G. G. NASCIMENTO* \\ Instituto Federal de Educação, Ciência e Tecnologia do Rio Grande do Norte - Campus Natal Central \\ gerson.nascimento@ifrn.edu.br
}

Artigo submetido em dezembro/2014 e aceito em dezembro/2014

DOI: 10.15628/geoconexoes.2015.2617

\section{RESUMO}

O presente trabalho teve como objetivo analisar a acessibilidade no bairro de Nova Betânia, que integra o município de Mossoró-RN, por ser esta uma localidade que está imersa em um processo recente, porém contínuo, de transformação e que, em decorrência deste fato, tem apresentado grande demanda de deslocamentos. Sendo assim, para a melhor percepção da temática, trouxemos no primeiro capítulo um referencial teórico que versa sobre dois importantes conceitos: Mobilidade Urbana e Espaço Urbano. No segundo capítulo foi feita uma contextualização histórica da cidade, através do fornecimento de informações imprescindíveis para o entendimento da atual dinâmica de organização espacial. Além disso, foi apresentado um panorama da situação dos transportes na cidade como um todo e mais detalhadamente no recorte urbano foco do trabalho. Foi observado que a quantidade de veículos de transporte coletivo que atende a cidade é insuficiente diante do quantitativo populacional, existe má distribuição de itinerários que resulta em várias linhas atendendo uma pequena área enquanto grande parte é desassistida, além de outros problemas como a falta de rigor no cumprimento de itinerários e o estado de conservação da frota, pontos de parada, dentre outros. Enquanto procedimento metodológico, recorremos à bibliografia relacionada à temática abordada bem como a um trabalho de campo na qual foram realizadas entrevistas formais e informais, consulta a órgãos públicos e privados e visitas in loco na área objeto de estudo. Através dessa análise, concluímos ser de baixa qualidade o serviço de transporte prestado à população, culminando na insatisfação coletiva. Identificouse a necessidade de uma melhor gestão por parte das autoridades competentes levando em consideração a distribuição da população no espaço, bem como as principais demandas nos deslocamentos.

PALAVRAS-CHAVE: Transporte Coletivo. Mobilidade Urbana. Cidade de Mossoró

\section{URBAN MOBILITY: AN ACCESSIBILITY ANALYSIS IN THE NEW BETHANY NEIGHBORHOOD OF MOSSORÓ-RN}

\begin{abstract}
This study aimed to analyze the accessibility in the neighborhood of Nova Betânia, which integrates Mossoró $\mathrm{RN}$, as this is a location that is immersed in a recent, however continuous, process of transformation and that in consequence of this fact, has shown great demand of displacements. Thus, for better understanding of the subject, is brought in the first chapter the theoretical background which deals with two important concepts: Urban Mobility and Urban Space. In the second chapter was made a historical context of the city, by providing information essential to understanding the current dynamics of spatial organization. In addition, an overview was presented of the transport situation in the city as a whole and in detail in clipping urban focus of the work. It was
\end{abstract}

observed that the amount of public transport vehicles serving the city is insufficient before the quantitative population, there is poor distribution of routes that results in several lines serving a small area while much is unattended, apart from other problems such as lack of rigor in fulfilling itineraries and condition of the fleet, bus stations, among others. It is through this analysis that concluded to be low quality transportation service provided to the population, culminating in collective dissatisfaction Identified the need for better management by the competent authorities taking into account the population distribution in space, as well as major demands of displacement.

KEYWORDS: Public Transport. Urban Mobility. Mossoro City 


\section{INTRODUÇÃO}

Historicamente as cidades se desenvolveram a partir do conceito de reunir em um mesmo espaço as diversas atividades humanas; comércio, serviços, lazer, alimentação, moradia, etc. Organizadas dessa forma, todas as necessidades da população eram concretizadas à distância de apenas algumas quadras e mesmo as mais distantes não comprometiam a interação e a complementaridade entre as diversas atividades. A proximidade entre o local de trabalho, de compras e de residência, davam ao cidadão a comodidade e a liberdade na apropriação do espaço urbano, já que nesse contexto todas as atividades estavam praticamente ao alcance de todos.

Entretanto, a aceleração da urbanização vem impondo uma nova dinâmica à sociedade. As exigências por mudanças são constantes, mas a adaptação ao novo ritmo dos acontecimentos tem sido difícil para grande parte da população. O processo necessário de apropriação do espaço urbano tem se deparado com obstáculos de complexa solução, um deles diz respeito ao deslocamento das pessoas em busca dos locais onde podem realizar suas atividades diárias; realidade vivenciada em muitas cidades do Brasil sejam elas de grande, médio ou pequeno porte.

Nesse contexto, tem-se notado que o município de Mossoró-RN se enquadra no perfil recém-descrito, e que sua população tem experimentado, cada vez mais, as consequências decorrentes da má administração no setor de transportes públicos. Essa realidade aponta a urgência de medidas que possam efetivar uma ampla mudança nesse processo, culminando no provimento de qualidade de vida à população através da mobilidade urbana.

Este estudo teve como recorte espacial uma região situada em uma área periférica do município. O espaço citado integra o bairro Nova Betânia, um dos bairros de mais alto padrão na cidade, e que está progressivamente se transformando em uma área de destaque em virtude da recente implementação de importantes estabelecimentos comerciais, educacionais e de habitação.

A escolha do recorte espacial se justifica, pois, em virtude da capacidade de atender as necessidades de distintas classes econômicas, esta área está cada vez mais presente no dia-a-dia da população, e como efeito dessa oferta variada de serviços, observou-se que a ocupação deste espaço está favorecendo a transformação de uma área antes quase despovoada em uma nova centralidade. Entretanto, observou-se que apesar de todos os apontamentos acerca de sua capacidade de abrangência no atendimento à população, a área citada apresenta uma infraestrutura, no que tange à locomoção, muito insatisfatória. Dessa forma, o presente estudo objetiva analisar a acessibilidade no bairro de Nova Betânia, por entendermos que os problemas identificados nessa localidade refletem as dificuldades vivenciadas no setor de transportes como um todo.

\section{MOBILIDADE URBANA: UMA POLÍTICA NECESSÁRIA NAS GRANDES CIDADES}

A Mobilidade Urbana é um dos temas de maior relevância a ser considerado no processo de gestão de uma cidade, pois ao inserir essa realidade na dinâmica urbana abrimos espaço para o desenvolvimento econômico, social e para a inserção democrática da população no espaço. Todos esses fatores são essenciais para que haja qualidade de vida. Sendo assim é imprescindível 
compreender o conceito de mobilidade urbana sob uma visão holística, levando em consideração a complexidade dos processos de deslocamento.

Para melhor compreendermos esse conceito e sua importância na vida da sociedade atual é necessário um olhar sistêmico sobre o objeto de estudo, ou seja, significa dizer que a mobilidade compreende um conjunto de elementos necessários aos deslocamentos de toda a população. Trata-se, portanto, de um sistema, este sendo formado por várias etapas que se inter-relacionam em prol de um único objetivo que é o bem estar e a comodidade de todos os usuários de transportes de todas as categorias que se deslocam na cidade todos os dias.

Nesse contexto, cada etapa de um deslocamento tem sua importância no sistema de mobilidade. Em estudos sobre o tema, Macedo; Silva e Costa (2008) exemplificam que esse encadeamento de etapas, chamado de cadeia de mobilidade, pode ser constituído pelo trecho percorrido a pé da origem (casa, trabalho) até a linha de ônibus mais próxima; espera e deslocamento por ônibus até terminal ou estação de transbordo para acesso ao modo de maior capacidade (ônibus articulados, trens ou metrô) seguido do deslocamento a pé até o destino final (casa, trabalho, etc.).

O bom funcionamento das estruturas para a realização de cada uma dessas etapas é imprescindível para que o sistema atinja o seu objetivo final. Nessa análise quando alguma dessas fases é realizada sem a devida infraestrutura, avalia-se que a mobilidade naquela localidade é reduzida e prejudica a população, principalmente àquela que utiliza o transporte público. Dessa forma, essa medição é feita a partir do nível de facilidades que as pessoas têm para percorrer seus trajetos até os destinos finais. Essas facilidades se traduzem, sobretudo, na aparelhagem proveniente do poder público, pois o Estado é o principal responsável pelo bom funcionamento dos sistemas de mobilidade.

\section{O ESPAÇO URBANO: AS CONTRADIÇÕES DE QUEM O PRODUZ}

O conceito de espaço urbano sofreu - e ainda sofre - diversas modificações ao longo da história e dos vários contextos do estudo da Geografia, desse modo, não pretendemos fundamentar nosso trabalho na discussão do conceito, mas na exposição das características concernentes ao espaço, acreditando que a apresentação dessas particularidades se constitui como melhor meio para a elucidação do tema.

Sobre a referida ausência de apenas um conceito de espaço, Correa (2003, P.19) expõe sua opinião através do pensamento de David Harvey. Ele afirma estar "de acordo com Harvey (1973) quando este argumenta que as diferentes práticas humanas estabelecem diferentes conceitos de espaço, conceitos que sob certas circunstâncias são por nós empregados."

Ainda sobre o tema, Castells (2006, P. 192) expõe que

“[...] não existe teoria específica do espaço, mas simplesmente desdobramento e especificação da teoria da estrutura social, para prestar conta das características de uma forma social particular, o espaço, e de sua articulação a outras formas e processos dados historicamente".

O autor aponta o espaço urbano como uma "forma social", resultado da ação antrópica e, é através dessa afirmação que ressaltamos a relevância do papel da sociedade enquanto 
formadora e transformadora desse espaço. Referimo-nos, nesse contexto, aos movimentos não aleatórios realizados pela sociedade. Ao classifica-los como não aleatórios estamos também afirmando que o espaço não é criado e transformado fortuitamente, mas que esse processo é realizado intencionalmente de acordo com os interesses dos grupos que compõem a coletividade nos contextos de cada época.

Sobre essa questão Castells (2006, P. 182) afirma que "o espaço urbano é estruturado, quer dizer, ele não está organizado ao acaso, e os processos sociais que se ligam a ele exprimem, ao especifica-los, os determinismos de cada tipo e de cada período da organização social.". Destacamos, segundo o autor, como responsáveis por esses processos os chamados agentes produtores do espaço, uma vez que são esses grupos que, em busca de atender seus interesses, modelam e/ou transformam o solo urbano. Entretanto, seus interesses são, muitas vezes, divergentes, fazendo com que essa contradição seja uma característica marcante no referido processo. Harvey (2005, P. 55) elucida que "[...] o espaço urbano criado pelo capitalismo também é visto como lugar da contradição e da tensão, e não como expressão do equilíbrio harmonioso."

$\mathrm{Na}$ concepção do autor, isso ocorre porque o espaço urbano é o palco do desenvolvimento das relações capitalistas, estas, por sua vez, são contraditórias. Ou seja, através das relações de produção e acumulação de capital é que a sociedade vai esculpindo as paisagens, transformandoas segundo as necessidades dessas relações. Dessa forma, o desenho adotado no espaço urbano não poderia ser livre de contradições, e ainda menos livre da predominância dos interesses dos grupos que detêm o direito à propriedade e aos meios de produção.

SPOSITO (2000), afirma que a cidade é o lugar mais propício para o desenvolvimento das relações capitalistas. Segundo a autora

A cidade é, particularmente, o lugar onde se reúnem as melhores condições para o desenvolvimento do capitalismo. O seu caráter de concentração, de densidade, viabiliza a realização com maior rapidez do ciclo do capital, ou seja, diminui o tempo entre o primeiro investimento necessário à realização de uma determinada produção e o consumo do produto. A cidade reúne qualitativa e quantitativamente as condições necessárias ao desenvolvimento do capitalismo [...] (SPOSITO, 2000, p. 64).

Assim, ainda na concepção da autora, a cidade é ao mesmo tempo produto e produtora das relações estabelecidas sob a égide do modo de produção capitalista. Sobre este fato, ela ainda expõe que

Esta produção social das formas espaciais é ao mesmo tempo manifestação e condição do estágio de desenvolvimento das forças produtivas sob o capitalismo. Nesta perspectiva, estamos falando do espaço como concretizaçãomaterialização do modo de produção determinante no caso o capitalista, e a cidade como uma manifestação desta concretização (SPOSITO, 2000, p. 64).

Desse modo, ao admitirmos a importância do papel das relações sociais na construção do espaço urbano, necessitamos perceber a função dos agentes produtores do espaço em cada etapa dessa transformação que é constante, como influenciam e como são influenciados. Essa necessidade ocorre, de acordo com Castells, uma vez que ao 
Analisar o espaço urbano enquanto expressão da estrutura social resulta, consequentemente, em estudar sua modelagem pelos elementos do sistema econômico, do sistema político e do sistema ideológico, bem como pelas combinações e práticas sociais que decorrem dele (CASTELLS, 2006, p. 193).

Sendo assim, o aprofundamento na questão dos agentes produtores do espaço se justifica por estes sofrerem a influência de todas as práticas e sistemas citados pelo autor, ou seja, eles são, concomitantemente, elementos dos sistemas econômicos, político e ideológico bem como responsáveis pelo estabelecimento das combinações e práticas sociais que se materializam no espaço urbano.

\section{CONSIDERAÇÕES FINAIS}

O transporte público é um importante aliado da inclusão social, pois é através dele que uma população exerce o seu direito às oportunidades disponibilizadas no espaço urbano. Estamos falando, dessa forma, da efetivação do direito de ir e vir, e, portanto, nos referindo ao conceito de mobilidade urbana.

O referido conceito trata desse direito à apropriação dos espaços da cidade bem como dos seus equipamentos e serviços. Dessa forma, há mobilidade quando a população tem plenas condições de igualdade de conveniências para alcançar os destinos almejados, ou seja, a mobilidade urbana é medida não só através da quantidade de destinos alcançados pelo sujeito como também pelas facilidades que este encontra nos processos de deslocamento.

Ao falarmos de facilidades estamos nos referindo às condições indispensáveis para que o sistema de transporte coletivo seja considerado de qualidade. São condições que não se limitam apenas ao âmbito dos serviços oferecidos pelas empresas particulares, que se ocupam do deslocamento propriamente dito. Trata-se de toda uma infraestrutura indispensável para o adequado funcionamento do setor. São fatores como a conservação da malha viária, sinalização vertical e horizontal, construção e conservação dos pontos de parada, segurança, dentre outros.

Ainda sobre as facilidades, podemos entender que apesar de perpassar o âmbito das empresas privadas, há também para estas, inúmeras exigências em relação à prestação do serviço. A parcela que fica sob a responsabilidade delas é tão importante quanto todas as outras citadas. Inclusive, é esse serviço o alvo das principais reivindicações da população.

O transporte está intrinsecamente ligado a todos os outros serviços básicos, uma vez que é através dele que as pessoas podem alcançar os destinos onde eles estão estabelecidos. Para aqueles que utilizam veículo próprio esse acesso é facilitado, visto que as políticas públicas vêm priorizando a construção de estruturas que são muito mais utilizadas por esses veículos. Esse cenário é um dos responsáveis pelo incentivo ao uso deste meio de locomoção.

Já o setor de transportes públicos experimenta um período de decadência. Não tem a devida atenção por parte dos seus gestores e desse modo não vem servindo bem ao propósito de promover a mobilidade e acessibilidade de forma democrática à população. As consequências são sentidas por todos, entretanto, é nas classes menos favorecidas que se concentram os maiores impactos. São pessoas que não encontram as condições necessárias para o deslocamento através do transporte público e que também não dispõem de outros meios locomoção, ou seja, são os mais pobres que sofrem a segregação socioespacial. 
Os conceitos de exclusão social e pobreza vão além das questões relacionadas à renda, pois a pobreza é um fenômeno de várias dimensões. Os excluídos não são apenas aqueles que não têm renda suficiente para satisfazer as necessidades básicas (como moradia, vestuário, alimentação), mas também aqueles que são privados do acesso aos serviços essenciais, e aos direitos sociais básicos.

Ao reunirmos e interpretarmos os dados sobre a prestação do serviço de transporte coletivo urbano em Mossoró, e mais especificamente na NC, pudemos constatar que a acessibilidade na localidade é precária e que apesar dessa realidade a demanda pelo serviço de ônibus não é grande, se considerarmos o número de viagens e o número de passageiros por dia. De posse dessas informações podemos afirmar que não há, nesta população, a cultura da larga utilização desse serviço. Como causadores da situação apontamos a baixa qualidade apresentada na prestação do serviço como um todo.

Apesar da baixa procura pelo ônibus, há um grande número de frequentadores na NC, caracterizando-a como importante área no contexto da cidade e até mesmo do seu entorno. Dentro desse contingente de pessoas, há aqueles que necessitam acessar a área com muita ou pouca frequência, para fazer compras ou em busca de lazer, e há também os precisam ir e vir diariamente para estudar e/ou para trabalhar. O que eles têm em comum é o direito de ser cidadão e de ter oportunidade se apropriar dos espaços e estruturas espalhadas pela cidade, assim como qualquer outro membro da sociedade.

Promover a não exclusão é, sem dúvida, uma incumbência do governo, já que este é o principal detentor da responsabilidade social. No entanto é indispensável uma revisão na questão cultural, pois em um modelo capitalista, que favorece a diferenciação social, um bom - e essencial - primeiro passo seria a sensibilização da população para com os seus semelhantes.

\section{REFERÊNCIAS}

1. CARLOS, Ana Fani Alessandri. O Espaço Urbano: Novos Escritos sobre a Cidade. São Paulo: Labur Edições, 2007, 123p.

2. ROLNIK, Raquel. O que é a cidade. São Paulo: Brasiliense, 2012.

3. SPOSITO, Maria Encarnação Beltrão; ELIAS, Denise; SOARES, Beatriz Ribeiro. Agentes econômicos e reestruturação urbana e regional: Passo Fundo e Mossoró. São Paulo: Expressão Popular, 2010.

4. GOMIDE, Alexandre de Ávila. LEITE, Sabina Kauark. REBELO, Jorge. Transporte público e pobreza urbana: um índice-síntese de serviço adequado. Brasília: Ipea, 2006 (Texto para discussão, n. 1209).

5. GOMIDE, Ávila A. Transporte urbano e inclusão social: elementos para políticas públicas. Brasília: Ipea, 2003. (Texto para discussão n. 960).

6. GROSTEIN, Marta Dora. Metrópole e expansão urbana: a persistência de processos insustentáveis. São Paulo em Perspectiva, Revista da Fundação Seade, São Paulo, v.15, 2001.

7. SPOSATI, Adaíza. Exclusão social abaixo da linha do Equador. Texto da apresentação no seminário sobre exclusão social realizado na PUC/SP, em abril de 1998.

8. FREITAS, Juciara Conceição. Transporte coletivo em Natal/RN: Uma abordagem geográfica. 
2011. Dissertação (Mestrado). Universidade Federal do Rio Grande do Norte, Natal.

9. NASCIMENTO, Gracileide Ferreira. Território usado e transporte coletivo: mobilidade e acessibilidade no Bairro Lagoa Azul - Natal/RN. 2010. Dissertação (Mestrado). Universidade Federal do Rio Grande do Norte, Natal.

10. ROCHA, Aristotelina Pereira Barreto. Expansão Urbana de Mossoró (período de 1980 a 2004): geografia, dinâmica e reestruturação do território. Natal: EDUFRN Editora da UFRN, 2005. f. 292.

11. DUARTE, Fábio. SÁNCHEZ, Karina. LIBARDI, Rafaela. Introdução à mobilidade urbana. Curitiba: Juruá Editora, 2007. 